\title{
Market Positioning of Kalco's Virgin Coconut Oil (K's-Vco) as a Functional Food
}

\author{
Gowtham Ashirvad Kumar, A.Ravikumar
}

\begin{abstract}
To assess the Positioning and Marketing potentials of KALCO's Virgin Coconut Oil (K's-VCO) only in the perspective of being consumed as "Functional Food" .To understand the characteristic, receptiveness and response of potential consumers to the introduction of a new product category "Functional Food".This study attempts to test and establish the factors that will influence and drive the market creation for oils as functional food .To asses and ascertain the possible channels of distribution and supply chain for the products first placement into market.
\end{abstract}

Keywords : KALCO and, Virgin Coconut Oil endeavor,

\section{INTRODUCTION}

\section{a. Job Satisfaction:}

Marketing of a concept, in this technology driven consumer economy is characteristically dynamic and volatile. Hence it is compelling to engage with a marketing model that is to be tested to derive maximum data to construe marketing information out of the same. When societal media engineering and online sales portals are the dominant channels that provide a platform for positioning a product or a concept to reach to the mass market translation the marketing of a concept such as newly founded "Oil as a functional food" is very challenging. Hence it become critical to strategically position the product or the Concept based on assumed market response and reaction towards what is being positioned. [1],[ 3],[5] While the market response is determined by the user experience when a product is positioned and tested after the cycle of conceptualization and product development. It takes more steps to reach the market when a "Concept Oriented Product" has to be positioned in the market. While an established product has a place in the mind map of consumers it allows the consumers to make a choice only based on the competitive products in the market or the alternative products in the market. [2 ],[ 4],[6]

In the case of "Concept Oriented Product" the acceptance of the concept is key to placement in the market. The information backing up the "Concept Oriented Product" should be so strong and undisputed and backed up by a 360

Revised Manuscript Received on July 22, 2019

Gowtham Ashirvad Kumar, Department of MBA,Bharath institute of Higher Education \& Research,Tamilnadu,India Email: kgowthamaashirwad123@gmail.com

Dr.A.Ravikumar, Associate Professor,Department of THM,Bharath institute of Higher Education \& Research,Tamilnadu,India ravikumar.th@bharathuniv.ac.in

Third Author Name, Department of MBA,Bharath institute of Higher Education \& Research,Tamilnadu,India

degree foolproof data backup. Once these are in place the "New mind-map" or "Perceptual map" creation for such product existence has to begin with the education, the education should be compelling and emphasizing on the personal and emotional values not only of the self but also of their future generation followed by the social inclusiveness. Education should be followed up with sensitization or creation of awareness, it is compelling to associate with the media to enhance percolation of the concept into the mind-map and then other steps of enhancing visibility and reach to grow the mind map is relevant to the concept positioning and marketing that translates to selling. It is therefore important to strategically evaluate what are the factors that drive the conceptualization that are critical to make the Concept appear compelling and appealing to the consumers. It is always either the experience of a product or the understanding and relating of the concept to and assumed solution, which initiates a want and then a need that leads to creation of a market.

User experience is always associated with the fully mature product where the supply-demand gap has been identified. However, for a Conceptual Product existing in the market, being promoted under value added food, for it to make a shift to be marketed as a conceptual food, it is manifold challenge to make the consumers unlearn and disassociate with their attributes relating to the virgin coconut oil as "Oil" and relearn and re-associate Virgin coconut oil as "Functional food". [7],[ 9] ,[11]

Indian consumer market is characterized by a low tendency to adapt to unproven concepts and such concept based products. It reacts unpredictability to such products and a negative reaction is very quick and seemingly destructive to the product line. If the concept is nascent and emergent the volatility index of the concept and the associated products is very high. The acceptance period of the concept oriented market is long and emotional acceptance and not informed acceptance, therefore a rationale is not put in judgment before disengaging with the product or concept. The market reacts more sentimental rather than making more informed decisions and sentimental reactions are very quick and destructive to not only the product but to the entire ecosystem. It still more difficult to market a created concept and make it achieve Nash equilibrium, in percolation into such abrasive and buoyant market-scope, such as in Indian consumer market. [8],[ 10] ,[12]

Positioning a concept to be accepted in the Indian market is highly challenging and a thoroughly researched strategy is essential before positioning the concept based product into the marketing and supply chain lines of distribution. [13], [15], [ 17] 
Having set the premise of the problem statement, we need to understand the ecosystem and define an approach to engage and solve the problem and execute the solution to overcome the challenges.

The Indian Consumers and their behaviors are typically characterized by factors such as Age, Literacy, Income and the interplay off all these factors put together. India is the youngest country with $40 \%$ of its population age group of 18 to 35 and the working population at the age of 21 to 45 is positioned at 60\%[14],[ 16], [18]

The product consumption in Indian context is characteristically driven by quality, it is appropriate to introduce a term called "Continuously Relevant Quality" which is the continuous offering of similar quality by content and sensory perception that remains to be relevant to all times and age groups. Marketing a concept driven product has its own challenges. It has to have an end to end seamless arrangement of critical components like the sensitization and awareness program, it has to have a color apart from the corporate color and we need to have a differentiator in place to stand out of crowd. [19],[21],[23]

Concept Characterization: Food defined and Function defined

Functional food is a subset of food. Food offers two characteristic function of

1. Providing energy to the metabolic functions and to the body and the organism to carry out its routine functions of life.

2. Provide the building blocks for repairing and replacing damaged parts of the body. Anything qualifies to be food if the above two functions are obtained through the normal course and process of ingestion, digestion, assimilation and ejection while adapting and passing through course in the specific tract. [20],[ 22], [24]

Life process has specific functions and needs to maintain a harmonious functioning as a whole. The food that offers to drives the specific functionality by going through the normal course of food intake and digestion is called functional food. The concept of "functional food" was introduced in Japan in the 1980s. Since then various efforts have been made to define functional foods (Mandeep Ahuja; 2010).

"Functional foods" are food products that consist of vital nutrients that go beyond simply nurturing usual growth and development of an individual. Fortified with nutritional and disease-preventing qualities, consumption of such food is with an intention towards improved wellbeing, prolonged existence and prevention of chronic diseases. Food Safety and Standards Authority of India (FSSA 2006) definition of functional food is relevant in Indian context - Broadly

"Functional food" may be defined as a food which influences specific functions in the body that may provide added health benefits or remedy from some diseased condition following the addition/concentration of a beneficial ingredient, or removal/substitution of an ineffective or harmful ingredient. Foods might inherently possess these supposedly beneficial qualities, or they may be functional/modified and/or genetically altered". [25],[27],[29]
Functional foods let consumers eat augmented foods close to their natural state, instead of consuming dietary supplements manufactured in liquid or capsule form. Functional foods are either enriched or fortified which restores the nutrient content in a food back to similar levels from before the food was processed. Health Canada defines functional foods as "ordinary food that has components or ingredients added to give it a specific medical or physiological benefit, other than a purely nutritional effect.

Functional Food Sector is an emerging concept targeting the health consciousness \& wellness sector. It is a sector which offers products and services for the pro-active health care. Most of the time the functional food has overlaps and stand undifferentiated from the range of wellness products. The differentiation may exist between therapeutics and natural food. However, the differentiation between Functional food, Nutraceuticals, Probiotics, and Prebiotics are all vague.

The difference between the Therapeutic systems and food systems is that the food systems goes through the normal existing metabolic process of an individual and travels the assimilation and storage path yet delivered a remedy to the function that may be defunct/non-functional or inefficiently functional. Example consumption of fiber rich food will relieve constipation. Whereas the therapeutic molecules are to supersede all the metabolic systems and defense mechanisms of the body and is supposed to penetrate all barriers to reach the target area. The excess residues will have to find the forced excretory path while it stresses the renal system.

Food vs. Supplements

[https://www.nutraceuticalsworld.com/issues/2013-11/view _features/functional-foods-20-a-natural-evolution]

Many companies have been misled over the last 15 years to think the functional food category must compete with supplements - offering the same benefits but in a food form. However, the biggest successes have come where functional foods have focused instead on benefits that are a strong and logical fit to food, or on benefits that supplements cannot yet provide.

Trying to carve out a slice of an already established supplements market has proven a hard road. The hype over functional food similar for example cod liver oil offering the clinically effective dose remains steady, even while sales are a free-fall. The reason is supplements market already has "share of mind" with consumers as the most effective way to obtain the benefit. It's also the cheapest, with the cost per day of supplements about $35 \%$ below that of beverages.

In France, for example, magnesium milks were briefly marketed, and have largely disappeared, because French people were already spending $\$ 110$ million a year on magnesium supplements, which offered a higher (and more effective) dose than a glass of milk and at a lower cost per dose. [26],[28],[30]

Foods and beverages cannot be a carrier for every benefit-taste, dose and format all play a role in success - and if the benefit the food is offering is already "owned" by a supplement category, the challenge becomes even greater, as supplements may be significantly cheaper per dose. It's better to focus on "food values" and "beverage values" and offer benefits 
where foods and beverages have a competitive advantage (as with dairy and protein) or seem "more natural" as a way of getting the benefit. [31],[33]

\section{REVIEW OF LITERATURE}

All the relevant information that is needed for the proof and analysis that lead to the formation of the hypothesis. 1. Products in food market and the evolution of consumer consciousness

2. Enormous work has been done based on concept selling in the early 1980

3. Literature defining functional food and differentiating the same from closely related concept have since accumulated to evince interest in their studies. [1], [3],[5]

Functional foods which are already available in the Indian market include those with removal of an allergic protein (gluten free atta), those containing live bacteria (probiotics, prebiotics) such as Yakult health drink and Amul's butter milk or those containing some health nutrients such as energy bars, juices and soy-based products. In addition to the various health benefits, functional foods also present economic benefits as they give higher profitability margin as compared to conventional foods. Retail prices of functional foods are typically 30 to 500 percent above the comparable conventional foods and the global market size has been estimated between US\$30 and US\$60 billion with Japan, United States, and Europe being the leading markets. Developing countries have started to emerge as exporters to cater to the increasing demand in the developed countries. [2 ], [4],[6] Moreover, demand for functional foods with in the developing countries is growing, presenting a lucrative opportunity to develop domestic markets. Due to exceptional growth of the Indian economy and higher purchasing power parity (PPP) of the consumers in the last decade, consumers are moving towards specific functional foods. Urbanization, changing population demographics and a strong desire among Indian consumers to maintain a healthy lifestyle are additional factors driving this market. Although this is a new concept in our country and the market is still in infancy but the demand for functional foods would continue to increase due to their specific health benefits [7],[9],[11]

Literature pertaining to the concept and Product knowledge

Throughout this study it is this definition that will be applied for clarity of understanding. The functional component and the technical and scientific basis of the functionality have been clearly established in the past. Despite the fact that the definition of functional food has been understood there is scanty literature that specifically elucidates the relationship between establishing a market by using the notional concept of a functional component as a food. Functional food cannot be a single well-defined/well characterized entity (Roberfroid, 2002). The concept of Functional Foods has been adopted differently by the countries across the globe. The differences lay in the definition and thereby the scope and the regulatory framework that governs the market. [8],[ 10], [12] The concept of functional food was first promoted in 1984 by Japanese scientists who studied the relationships between nutrition, sensory satisfaction, fortification and modulation of physiological systems (István et al.,2008).
There it referred to the food products fortified with special constituents that possess advantageous physiological effects (Hardy, 2000; Stanton et al., 2005). [13], [15] ,[ 17]

\section{RESEARCH METHODOLOGY}

The research methodology adopted in the present study was broadly related to the choice of the study area, collection of data, and tools of analysis.

Significance of the study

This study attempts to create a new market space with revolutionary product line for wellness product. The categorization of a very vaguely defined yet most critically need category of food needs to find a space in the market with less stringent regulations and tax implications. This study attempts to prove that such food category which offers a very vital aspect of a specific function into as a cure and not just as nutrient but beyond the subject of medicine. [14],[16], [18] This study will enable to identify and group the product under a wellness category and can offer a healthy society by targeting the essential function for essential group of people who will be in need. This will subject the policy makers to rethink about the nutrition programs of the nations. Those underperforming or non- performing products will be able to get a light into the market. What is called as Nutraceuticals shall be called as Functional food because it offers no cure or prophylaxis it just is integrated into the food and diet to offer a balance in the wellness of functions. [19],[21],[23]

\section{OBJECTIVE}

1. To assess the Positioning and Marketing potentials of KALCO's Virgin Coconut Oil (K's-VCO) only in the perspective of being consumed as "Functional Food"

2. To understand the characteristic, Receptiveness and response of potential consumers to the introduction of a new product category "Functional Food"

3. This study attempts to test and establish the factors that will influence and drive the market creation for oils as functional food[20],[22], [24]

4. To asses and ascertain the possible channels of distribution and supply chain for the products first placement into market.

\section{AREA OF STUDY}

The area covered for study was the city of Coimbatore, Tamilnadu (TN). Characteristically typical Points of Sale (PoS) and retail were identified within the city. Twelve points of assessment and data capturing were selected to offer the questionnaire for due completion. Assistance was offered in terms of making them understand and also translate to Tamil or English. [25],[27],[29]

\section{METhODS OF DATA COLLECTION}

\section{Sources of Data}

Both primary data and Secondary Data were used in this study. The primary data were collected from the entire population of 100 respondents living across the areas specified in the Coimbatore City.

Besides, secondary data were also collected from census reports,

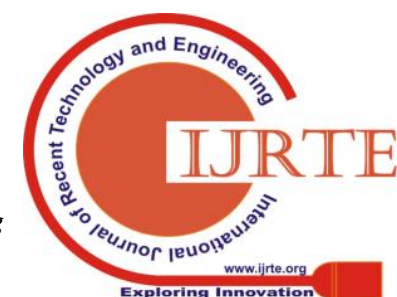


online statistics information gathered from and materials collected from books, journals, articles on them from different centers in the state. [26],[28],[30]

\section{A. Census and interview methods}

In order to study the Concept and Product Positioning, marketing strategies and distribution channels of the Virgin Coconut Oil (VCO) as Functional food some retail points of sale were selected. The study was explorative, since it was the maiden attempt of its kind to be undertaken in the state. Census and interview methods were used in this study. A pilot study was undertaken among twelve retail points across spread three regions and the respondents were contacted in person and in email, all the required information were collected in the pre-tested interview schedule. (Annexure)

\section{B. Data collection}

The following details were collected from the respondents Their Age, Gender, Living area, Family Income, Purchase capacity, Market access and their understanding of the concept of "Functional food" and the differentiation factors that will make them buy KALCO's Virgin Coconut Oil (K's-VCO) as a "Functional Food" and what marketing and distribution channels would be their preference. [31],[33]

Questionnaire Classified based on Design for Data accusation

A. Internal Drivers/Inherent drivers of Market (Secondary data generations) not driven by customers

B. External Drivers (Primary Data) the questionnaire is prepared to capture only the Primary data. The consumer response and the capture of their expectations are the ones noted in the questionnaire.

The Questionnaire items were segregated based on the index/drivers that enforce the customer's decision to buy.

Those included in the questionnaire are

\#1 [Cost Driver of Decision to Buy]

- Income/Affordability (Elite/Middle income groups are more affordable at the given cost)

- Cost planning and Off-setting (Judging their need of the product by offsetting budget on shift to use and gaps that exist on why they should choose to use VCO)

\#2 [Knowledge/Information/Literacy Drivers of Decision to Buy]

- Product information (technical Information and Usage)

- Perception by Urban and Rural

- Information on Health Benefits and Wellness index

- Belief System (Where will you buy it if the product must be a proof for health benefit?, Will you believe the product when it comes as a Prescribed or as an Over the Counter buying, Will you prefer to buy the product as Prescribed or OTC?)

\section{\#3 [Logistic \& Reach Drivers of Decision to Buy]}

- Social media engineering

- Positioning through Government incentivized/subsides schemes

- Retail channels- Online/Hypermarket/ Departmental stores/ Corner Stores
\#4 [Quality Conscious Driver of Decision to Buy]

- Buying based on recommendation| Compulsion | Prescription | Own decision

- Buying based on Certification as Organic or any other certificate

\#5 [User Experience Drivers of Decision to Buy]

- See| Test| Use| Experience| Buy|

- Perceptual Driver

- Sensory Perception

- Promotional and Emotional Drivers

- Creating recall values

- Branding Channels

- Push Market

- Pull market- creating the pull and compulsion and obsession to buy

- Youth Debates

- Engineering Social Media Network (How to make the concept go Viral)

- Branding Channels - Hotels| Canteen| Health Care Centers and Institutes| Prescriptions| Hostels | Big functions and Events| Exhibitions| Conferences| Contracts | Policy Debates|

Perceptual maps on choice made of cost | perceptual maps on choice made of literacy | perceptual maps for choice of brands

\section{A. Tools of Analysis}

Both descriptive and quantitative tools were used for the analysis of the data. Descriptive methods of analysis like simple averages and percentages were used in this study along with graphs and diagrams for easy understanding.

\section{B. Quantitative Tools}

\section{Chi square test}

A chi-squared test, also written as $\chi^{2}$ test, is any statistical hypothesis test wherein the sampling distribution of the test statistic is a chi-squared distribution when the null hypothesis is true. Without other qualification, 'chi-squared test' often is used as short for Pearson's chi-squared test.

Chi-squared tests are often constructed from a sum of squared errors, or through the sample variance. Test statistics that follow a chi-squared distribution arise from an assumption of independent normally distributed data, which is valid in many cases due to the central limit theorem. A chi-squared test can be used to attempt rejection of the null hypothesis that the data are independent.

\section{LIMITATIONS OF THE STUDY}

The core subject of focus in this study is a niche and nascent subject matter. So far, the studies have focused themselves around the aspect only as a concept being understood and marketed such as Insurance policies, Time-share products, Financial Products such as fixed deposits and mutual funds. Otherwise it would have had pilot scale marketing and focus on the user experiences and history of use and reference or benchmarked products to compare and relate to. This study is limited in availability of subjects or respondents who have thoroughly understood the concept of functional food. Differentiation of food from Medicine and drawing a line 
between Medicine, Organic food, Nutraceuticals, Probiotics and "Functional Food".

To add to the confusion there are more such products which are given so many names and with label claims of certification and as a wellness product without offering a technical proof of the function of the food being consumed. This limitation extends to the subject of extending the proof of concept to proof of performance of the product in the market through the product pilot marketing and trials.

\section{ANALYSIS AND INTERPRETATION OF DATA}

The collected data were carefully processed, suitably consolidated and tabulated and further used for analysis. The results were carefully interpreted so as to answer all the research objectives and the same had been reported in the following chapters.

CHI SQUARE TEST FOR PLACES OF THEIR OF SALES OF THEIR PRODUCTS

\begin{tabular}{|c|c|c|}
\hline 6 & 12 & 57 \\
\hline 14 & 7 & 4 \\
\hline
\end{tabular}

Solution:

1) Null hypothesis:

There is no significant in between Places of their of sales of their products 2) Alternative hypothesis:

There is significant difference in Places of their of sales of their products

\begin{tabular}{|c|c|c|c|}
\hline 6 & 12 & 57 & 75 \\
\hline 14 & 7 & 4 & 25 \\
20 & 19 & 61 & 100 \\
\hline
\end{tabular}

Calculated value $=\mathbf{3 4 . 2 0}$

Degree of freedom:

$\mathrm{V}=[\mathrm{r}-1][\mathrm{c}-1]$

$\mathrm{V}=[2-1][3-1]$

$\mathrm{V}=1 * 2=2$

- Table value $=5.99$ (constant) at $5 \%$ probability

Calculated Value $>$ Table Value

Hence It is significant

So Alternative hypothesis is accepted

Therefore Null hypothesis is rejected and alternative hypothesis is accepted.

CHI SQUARE TEST FOR PLACES OF THEIR OF SALES OF THEIR PRODUCTS

\begin{tabular}{|c|c|c|}
\hline 6 & 12 & 57 \\
\hline 14 & 7 & 4 \\
\hline
\end{tabular}

Solution:

1) Null hypothesis:

There is no significant in between Places of their of sales of their products

2) Alternative hypothesis:

There is significant difference in Places of their of sales of their products

\begin{tabular}{|c|c|c|c|}
\hline 6 & 12 & 57 & 75 \\
\hline 14 & 7 & 4 & 25 \\
\hline 20 & 19 & 61 & 100 \\
\hline
\end{tabular}

\begin{tabular}{|r|c|r|r|r|}
\hline \multicolumn{1}{|c|}{$\mathbf{O}$} & $\mathbf{E}=\frac{\mathbf{R . T} \times \mathbf{C . T}}{\mathbf{G . T}}$ & {$[\mathbf{O}-\mathbf{E}]$} & {$[\mathbf{O}-\mathbf{E}]^{2}$} & {$[\mathbf{O}-\mathbf{E}]^{2} / \mathbf{E}$} \\
\hline 6 & $\left(75^{*} 20\right) / 100=15.03$ & -9.03 & 81.462 & 5.42 \\
\hline 12 & $\left(75^{*} 19\right) / 100=14.26$ & -2.26 & 5.085 & 0.36 \\
\hline 57 & $\left(75^{*} 61\right) / 100=45.85$ & 11.15 & 124.379 & 2.71 \\
\hline 14 & $\left(25^{*} 20\right) / 100=4.97$ & 9.03 & 81.462 & 16.38 \\
\hline 7 & $\left(25^{*} 19\right) / 100=4.72$ & 2.28 & 5.202 & 1.10 \\
\hline 4 & $\left(25^{*} 61\right) / 100=15.18$ & -11.18 & 124.952 & 8.23 \\
\hline & & & TOTAL & $\mathbf{3 4 . 2 0}$ \\
\hline
\end{tabular}

\author{
Calculated value $=34.20$ \\ Degree of freedom: \\ $\mathrm{V}=[\mathrm{r}-1][\mathrm{c}-1]$ \\ $\mathrm{V}=[2-1][3-1]$ \\ $\mathrm{V}=1 * 2=2$ \\ Table value $=5.99$ (constant) at $5 \%$ probability \\ Calculated Value > Table Value \\ Hence It is significant \\ So Alternative hypothesis is accepted \\ Therefore Null hypothesis is rejected and alternative hypothesis is accepted.
}

\section{RESULTS \&DISCUSSSION}

1. The Respondents were receptive to the "concept of function food" subjected to conditions of cost and user validation.

The findings towards establishing the factors that influence and drive the market creation for oils as functional food was surveyed, recorded analyzed. The data from Table $1-6$, indicates that the gender did not influence the positioning and adapting patterns. However it was the literacy rate and the economics of the livelihood of each family was the one which influenced the acceptance and adaption potential of the concept. Thought the respondents were receptive to the concept of functional food they always attributed a minimum derived benefit out of the new concept positioning. The major benefits they expected are the Cost benefit and the ease of accessing to the product. The functional benefit did not directly drive their choice of buying however they were willing to adapt to the concept of functional oil category on specific conditions of having fulfilled the user experience and coming from authenticated source.

There was an unequal spread of respondent's in-terms of Gender distribution and Literacy rates, Economic Area of living and the Average monthly income of families. There was a $33 \%$ to $67 \%$ spread of men vs. woman who were subjected to the interview (TableNo1.). Most of the respondents were from the urban area representing a $64 \%$ over $21 \%$ and $14 \%$ of Semi-urban and rural areas respectively (TableNo2.). Significant percent (49\%) of the respondents were Post graduates and Graduates (22\%). A mere $3 \%$ sample was illiterates therefore the samples could be taken to be literates.

Significant percentage $(>65 \%)$ of the respondents were aware of the concept of functional food. Thought not directly they could not place this category under a specific name. After explanation they were able to place it under the "Functional Food" category. Literacy though did not make a contributing factor for decision making it helped in making an informed choice and not a random choice. (Table No3.) 2. The most preferred choice of Positioning and Marketing potentials of KALCO's Virgin Coconut Oil (K's-VCO) as "Functional Oil" was hyper market experience 
followed by the Departmental stores.

3. Online did not receive expected patronage for first position a concept driven product, despite promises of wellness quotients. The authentication for first positioning is expected to come from proven channels such as Medical practitioners and endorsements from governments. There are choices that were made out of the self prescription mode also. Almost $60 \%$ respondents preferred the first positing to come from the medical practice.

\section{Super markets, Hyper markets were the preferred choices of the possible channels of distribution and supply chain}

In the supply chain the highest patronage was received for hyper market with almost about $54 \%$ preferring to go and make a choice based on user experience.

\section{Suggestions}

\section{Consumer Economy Based}

1. Out of the various factors considered the study established that cost of the product and the income and purchase power of the individual were the primary drivers of decision making to accept and adopt to new concept-based products. The age, gender or literacy did not determine the choice they make.

2 . Of the 100 respondents $13 \%$ were of the upper income group $12 \%$ were of the middle income group, $54 \%$ of them are from the moderate income group and $21 \%$ were of the lower income group.

\section{Consumer Choice based}

3 . The choice of virgin coconut oil over cooking oil was significantly high with $82 \%$ of the respondents choosing virgin coconut oil instead of ghee and not coconut oil. The billing of the stores reduced for coconut oil and the virgin coconut oil increased indicating a 30\% increase and shift of consumption pattern.200 ml @ 95 rupees over $1000 \mathrm{ml} @$ 450 this will equate to selling $200 \mathrm{ml}$ more will generate more profit for $200 \mathrm{ml}$ X $5=1000 \mathrm{ml}$ which will cost $95 \mathrm{X} 5=$ 475

4. In anytime of a choice the response clearly indicated that there was a need for alternate oil instead of refined sunflower or safe oil. The response was irrespective of the price the migration was expected

5. The cost is the primary driver of choice however it was not very clear if the choice being made is consciously considered as a functional food or just another food.

$6.64 \%$ of the respondents in all the economic class put together had been choosing consciously as judged by the follow up questions all of which we related to health association and preventive and curative models. Few of the respondents went to the extent of expressing home remedies and alternatives for baby food. Hence it is clearly understood that a momentum and awareness of oil as a functional food can be positioned as a market driver.

7. However, on the long run the aspects of consumption and the competition that may ensue may disrupt the market. The safeguards and standards need to be defined such that this functional food market is not disrupted.

8. Patents of neonatal products in market such as soy proteins for lactose intolerance and diathermy Fibers based food for geriatrics also have their market acceptance only when it has adopted the medical store supply chain. However, we need more engagements and market research data done on making functional food as a retail chain value directly instead of creating a market through the medical store supply chain associative.

9. It is to be noted that the concept of functional food is more captivated than the food being organic certification or not. More than 232 respondents asked questions regarding the health benefits rather than the validation of the product through certificates such as HACCAP or Organic certifications.

10. Almost all the positive respondents were associating themselves with the environment as a decision driver

11. The current usage of coconut oil as oil as food, Nutraceuticals and perception of oil as a functional food the replacement chance of food to functional food had a $74 \%$ conversion rate of the costing was fitting the pocket in all the three income groups. However, the shift was primarily assessed based on costing where the shelf keeping units were the determinants.

12. While interviewing almost $64 \%$ of the respondents associated the product with the health benefit questions and were willing to shift to the usage of VCO as food and there were only $32 \%$ of the mid income group were willing to shift to the usage of VCO as functional food and the rest were willing to use it only as oil.

13. $100 \%$ response in the initial stages was the inability to differentiate food from functional food and they were unwilling to replace the concept of food with functional food. 14. There were $82 \%$ of positive response to use on the virgin coconut oil as a functional food and the choice was made with respective to the cost of the product and not the size of the shelf-keeping units.

15. The proof that establishes a linkage between notional perceptions of the product that is yet to hit the market as a tangible product is largely different from any product or services that will remain intangible.

16. It is a proof that the concept of Functional Food is a preferred category under which can be placed in comparison to Nutraceuticals or medicine or even Alternative systems of medicine. (The respondents are aware of the health benefits (wellness index) of VCO and are able to differentiate between VCO and Coconut oil)

17. Despite the fact that respondents are well aware of the health benefits this study is a Proof that Cost of Shelf Keeping units are the choice drivers than the Health Benefits known to them. However, cost per $\mathrm{ml}$ is not a concern for the consumers.

18. This is a proof that they prefer coconut oil to other oils in terms of direct consumptions preferring VCO to coconut oil (awareness of blending happening in Coconut oil with non-edible components) and VCO over Ghee because of the cost factor. However, they still prefer to have VCO in place of Rice bran subjected to continued availability and at affordable costs. Affordability is not in comparison to the Rice bran oil but in inherent capacity to plan their buying.

19. It is at this planning to buy is makes the costing of Shelf Keeping Units critical driver for buying decisions.

20. The choice of First placement is Medical shops thought the preferred choice of buying can happen at Hyper/Supermarkets compared to Corner store shops, 
Departmental stores or even online buying habits.

21. There were more respondents from the online digital survey; however it was a significant finding that the digital space users preferred to buy the "Functional Oil Food" from the Hypermarkets. The explanations owed by them was that the first user experience always begins at hypermarkets since they go to the hyper markets which are always attached to multiplex shopping malls. They find more time to spend in exploring rather than listed buying. But they also indicated that the they would take the "Concept of Functional food seriously only when placed through Medical Shop out lets rather than Organic Shop outlets. However, the responses failed to indicate that a medical shop does not offer an explorative shopping but enables only a planned and itemized shopping.

22. Preferred choice of Shelf Keep Unit size and comparative price in bulk shows more profitable than selling in bulk.

23. Though the bottom of the pyramid consumers have access to the Street Corner Shops, the respondents feel that buying it from hypermarket becomes a reason for them to visit and look, touch, feel, sense and experience before buying. They cannot buy it and store for a long period of time and at the same time they don't have to frequent the hype market since VCO is not a daily need that cannot be stored.

\section{DISCUSSIONS}

The market of functional food is driven by multifactorial choice and not a singularity driven factor. However, the endpoint decision is made only with a single significant factor of singularity basis. In the case of the choice being made in this study, the market awareness and product knowledge is foundation for making the choice however, the significant percentage of the respondents made the decision based on only cost affordability.

\section{Cost engineering and buying patterns:}

Shelf Keeping units and sizes that determine the price fit and leverage in affordability and planning the cash-flow systems. People preferred smaller shelf keeping units and this correlated with the availability of the products prescience online store and delivery on demand. The reason being the storability and getting stale or rancid was sited. Locally produced and locally consumed systems may enhance the sale volume indirectly primarily for the transfer of cost benefits to the consumer will reduce the cost and they have the assured quality for the simple reason that the quality control over raw material procurement is traceable to the producer and will ensure $100 \%$ consistency.

The buying pattern and social media engineering- online buying patterns or the choices were not indicative of any substantial choice driving factors. The choice was subjectively lifestyle driven and occupation-oriented choices to make ease of living and ease of operations better.

\section{Placement into the market channels,}

Tie up with big basket: We have taken into consideration the products already in market which are positioned as virgin coconut oil alone and have already gained brand perception in terms of either organic or as cooking oil brands. 24mantra, organic India, L-Oil of Vama oils (p) limited. All of them have taken Virgin coconut oil as cooking oil. As seen in literature and scientific reviews the wholesome properties of virgin coconut oil is lost if the temperature is pushed beyond 55 degrees. Hence the natural form can be retained only under biological temperatures. Though this may not become an educative differentiator this will be the selling point on increasing usage and application where specified benefits can be spelt out. Placing the products in the AYUSH lines are more critical to use as base material for medical formulations than placing in the restaurants, hotels, hostels and canteens where it will be primarily be used as cooking oil.

Generally, it was expected that the rural educated group to be unaware of the social trends and commerce channel however a $70 \%$ respondent who sought online supplies were from the rural background. Several engagements regarding the use of virgin coconut oil is trended on social media however no product was trended. It is to be classified that an 8 to 12 percent presence of mono laureate is considered to have the functionality to be delivered as food.

It is inconclusive that the function of Functional food can be mapped to the actual acceptance of Oil as the function of functional food. Therefore, there needs to be an elaborate and continuous research to understand that the idea of functional food is understood well and the choice and decision of buying it is made.

The validation on Oil as a functional food is quite a challenge because Oil is always associated with the cardiac issues it is therefore important to research further on how to place the line of supply into populating the product into the market. The Medical supply chain or the online platform or the Shelf-spaces exploring the Chanel's of first placement.

In our assumption that the health benefits and specific actions are to be associated only as the fountain of the molecule as food and not as medicine or as Nutraceuticals values. Several aspects of nutritional benefits have risen to the technical documentation of coconut oil or its incremental value-added products chain. However, placing coconut, coconut oil or its high value derivative have not been documented and has never offered a scientific approach as till date.

There has been a spurt of publications and research once the repost of Cambridge newsletter and British journal of medicine published the Nutraceuticals benefits of coconut oil larger engagements were taken up on how to improve the coconut oil as a value added and technologically robust functional system.

Coconut oil is being traded as a commodity and hence a regulatory impact will prevail. While the high value product derivatives will not attract regulatory hurdles however quality issues and market acceptance will be key.

Comparative cost being matched will definitely create a new market space for VCO while still keeping the market for coconut oil in their own relative prices.

The customer acquisition cost and the delta in cost of production is comparable and allowed leverage of playingb8ntonthe market. Rather than disrupting the coconut oil market it allowed a creation of new market and offers choice of coconut oil being consumed as functional food or to be used as a cooking medium.

The concept of oil as functional food can be made to gain 
popularity and reach, only if the middle-income group is kept as a reference and safe target group.

This study shows that they responded with no bias and were showing anguish in the current market which offers a lot of lifestyles products yet which are spurious. They were eager in questioning the health benefits and also were concerned about the validation of quality.

The first placement of the product in the supply chain system can happen through the retail stores if the cost is kept competitive to the rest of the oils that are uses irrespective of the source or quality. Cost becomes the disruptive system in enabling a market. A compelling cost to drive the decisions of buying is essential. This in relation to all the oil in the market including high value oils like ghee, olive oil and cod liver oil or almond oil. If we have to optimize the cost-engineering to supply chain volume sales can be done starting with the medical line supplies and then slowly penetrating it into local markets after demand has been felt. It can be sent to the corner stores for increasing reach. Decisively if the cost: profit ratio optimization is done the appropriate channels can be adopted for volume supplies.

Thrift has always been the mechanism adopted by the middle-income group to adapt to new lifestyles and hence they would trade off only when there are many fold benefits. Despite the fact that credit facilities and bonus offerings being made the larger population of India would prefer to work based on thrift rather than credit and this is established through this study. The high-income group however has proven its willingness to try new lifestyles at high cost which is driven by the credit card or credit incentivized mechanism or high earning debit card purchases. Therefore, to create a market for new concept to reach the high-income group, credit linked system like the online purchases, partnering with banks through pay back screams are the viability rather than adapting retail supply chains. The low-income group always expects subsidized systems to even try a new proportion of lifestyle. They are rigid to change and don't understand any value systems to them the only value system they understand is anything free they will try. Therefore it becomes irrelevant to target the bottom of the pyramid class. If we had to place the concept or the product it is compulsively to position it in the welfare schemes of the government.

A new model of concept marketing is being formulated to share the dividends of profit or loss in a manner that the producer and the ground level worker gets. For the sweat they drop they earn as much. The market linked volume based incentive declaration on the price of produce have been put to test.

Urbanization and globalization are driving the Indian consumer markets and the need for healthy variant of food is felt by the consumer who is exposed to an unhealthy lifestyle. Functional foods, as one of the solution, are being introduced by the food marketers in various categories like dairy products, edible oils and breakfast cereals. The market is growing at a fast pace and presents a tremendous growth opportunity for food companies. But for achieving consumer acceptance in long run, the marketers would have to focus on studying the consumer expectations, judicious product development, efficient distribution and effective communication.

\section{CONCLUSIONS}

This study on potentials of positioning a concept based product of KALCO Agro (P) Ltd, company's Virgin Coconut Oil (K's-VCO) received significant attention. This was the conclusion that was arrived after analyzing various factors that would influence the consumer's decision making and also bench the market ecosystem. The study also concludes with a fact that there is a gap between the demand and supply. The gap can be strategically capitalized if appropriate channels of first positioning the concept based product and also enabling and ensuring the last mind reach through appropriate retail points such as Hyper stores and departmental stores

\section{REFERENCES}

1) BharthVajan R., Ramachandran S.,Psychographic dimensions of training,2016,International Journal of Pharmacy and Technology,V-8,I-4,P-23727-23729

2) Balakrishnan P., Bharthvajan R.,A study on human resource planning in hospitals in Chennai City,2014,International Journal of Applied Engineering Research,V-9,I-22,P-7503-7507

3) Priyadarsini P., Bharthvajan R.,Role of emotional intelligence training programme in reducing the stress of the nurses,2014,International Journal of Applied Engineering Research,V-9,I-22,P-7411-7421

4) Kerinab Beenu G., Bharthvajan R.,Empirical analysis on the cosmetic buying behavior of young women in South India,2014,International Journal of Applied Engineering Research,V-9,I-22,P-7361-7366

5) Balakrishnan P., Bharthvajan R., Whistling in the wind,2014,International Journal of Applied Engineering Research,V-9,I-22,P-7586-7593

6) Krishnan B., Peter M.,Health hazards of Indian Bpo employee-an alarming issue,2014,International Journal of Applied Engineering Research,V-9,I-22,P-7336-7341

7) Kerinab Beenu G.H., Peter M.,Role of insurance in economic development,2014,International Journal of Applied Engineering Research,V-9,I-22,P-7532-7539

8) Balakrishnan P., Peter M., Priyadarsini P.,Efficiency of safety measures for wellbeing of employees in manufacturing industry,2014,International Journal of Applied Engineering Research,V-9,I-22,P-7376-7382

9) Anbarasi M., Praveen Kumar S.,Online sales promotions of herbal products and its effectiveness towards tanisha.com,2019, Indian Journal of Public Health Research and Development,V-10,I-1,P-195-200

10) Anbarasi M., Praveen Kumar S.,Various online marketing and promotions strategies to improve the validation towards the organic products in the pharmaceutical sectors, 2019,Indian Journal of Public Health Research and Development,V-10,I-1,P-263-269

11) Loganathan R., Praveen Kumar S.,Grievance handling a key factor for solving issues of employees in an organization,2014,International Journal of Applied Engineering Research,V-9,I-22,P-7483-7491

12) Loganathan R., Praveen Kumar S.,Study on preference of private label brands in super and Hypermarkets,2014,International Journal of Applied Engineering Research,V-9,I-22,P-7327-7335

13) Smitha M., Praveen Kumar S.,Understanding stress and its managementamong the nurses in Chennai city,2014,International Journal of Applied Engineering Research,V-9,I-22,P-7560-7565

14) Kerinab Beenu G.H., Praveen Kumar S.,A study on the investment behavior of Chennai investors in mutual fund schemes,2014,International Journal of Applied Engineering Research,V-9,I-22,P-7520-7525

15) Loganathan R., Praveen Kumar S.,Retention strategies key for organizational productivity,2014,International Journal of Applied Engineering Research,V-9,I-22,P-7443-7447

16) Pavithra J., Ganesan M., Brindha G.,State wise analysis of microfinance sector in India,2016,International Journal of Pharmacy and Technology,V-8,I-4,P-23417-23432

17) Pavithra J., Ganesan M.,A comparative study on microfinance in India and abroad,2016,International Journal of Applied Business and Economic Research,V-14,I-8,P-5471-5476

18) Pavithra J., Ganesan M.,A study on awareness and impact of micro-financial schemes,2016,International Journal of Applied Business and Economic Research,V-14,I-8,P-5449-5460 
19) Senthilmurugan P., Pavithra J.,Consumer preference towards organised retailing with reference to Big Bazaar,2014,International Journal of Applied Engineering Research,V-9,I-22,P-7469-7475

20) Senthilmurugan P., Pavithra J.,Implication of social media marketing in growing healthcare industry,2014,International Journal of Applied Engineering Research,V-9,I-22,P-7448-7456

21) Loganathan R., Pavithra J.,Consumer perception towards private label brand over other brands in super markets and hypermarkets,2014,International Journal of Applied Engineering Research,V-9,I-22,P-7355-7360

22) Kerinab Beenu G., Pavithra J.,Tradeâ€“off between liquidity and profitability in logistics industry,2014,International Journal of Applied Engineering Research,V-9,I-22,P-7398-7401

23) Kerinab Beenu G., Pavithra J.,A study on the prospective consumerâ€ $\mathbf{T M}_{\mathrm{S}}$ perception towards utility cars in Chennai city,2014,International Journal of Applied Engineering Research,V-9,I-22,P-7526-7531

24) Pavithra J., Dilli Babu P., Ambuli T.V.,A study on budgetary control at Maruti Service Masters, Chennai,2014,International Journal of Applied Business and Economic Research,V-12,I-2,P-151-161

25) Pavithra J., Dilli Babu P., Ambuli T.V.,A study on customer satisfaction of retro Garments Pvt Ltd, Chennai,2014,International Journal of Applied Business and Economic Research,V-12,I-2,P-381-391

26) Kerinab Beenu G.H., Pavithra J., Senthilmurugan P.,A study on the influence of promotional activities for TATA ARIA among consumers in Chennai,2014,International Journal of Applied Engineering Research,V-9,I-22,P-7572-7578

27) Vijayaragavan S.P.,An investigative expert that's general FBG sensors,International Journal of Mechanical Engineering and Technology,V-8,I-8,PP-1500-1505,Y-2017

28) Vijayaragavan S.P.,Equalization routing protocol for Wi-Fi sensor strategy,International Journal of Mechanical Engineering and Technology,V-8,I-8,PP-1662-1666,Y-2017

29) Karthik B., Kiran Kumar T.V.U., Vijayaragavan P., Bharath Kumaran

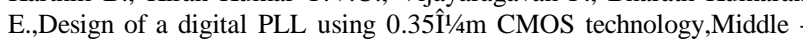
East Journal of Scientific Research,V-18,I-12,PP-1803-1806,Y-2013

30) Kanniga E., Selvaramarathnam K., Sundararajan M.,Kandigital bike operating system,Middle - East Journal of Scientific Research,V

31) Jasmin M., Vigneshwaran T., Beulah Hemalatha S.,Design of power aware on chip embedded memory based FSM encoding in FPGA,International Journal of Applied Engineering Research,V-10,I-2,PP-4487-4496,Y-2015

32) Jasmin M.,Optimization techniques for low power VLSI circuits,Middle East Journal of Scientific Research,V-20,I-9,PP-1082-1087,Y-2014

33) Jasmin M., Vigneswaran T.,Fuzzy controller for error control of on - Chip communication,2017 International Conference on Algorithms, Methodology, Models and Applications in Emerging Technologies, ICAMMAET 2017,V-2017-January,I-,PP-1-5,Y-2017

\section{AUTHORS PROFILE}

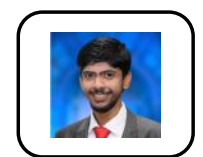

$\begin{array}{ccccc}\text { Gowtham Ashirvad Kumar, Department of } & \text { Kumation \& }\end{array}$



Dr.A.Ravikumar, Associate Professor,Department of THM,Bharath institute of Higher Education \& Research,Tamilnadu,India

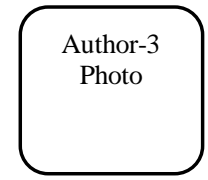

Third Author profile which contains their education details, their publications, research work, membership, achievements, with photo that will be maximum 200-400 words. 